\title{
La poesía visual de José Luis Castillejo. La aspiración de una escritura de lo inefable.
}

\author{
The visual poetry of José Luis Castillejo. The aspiration to achieve a \\ writing of the ineffable.
}

Esta obra está bajo una Licencia Creative Commons Atribución 4.0 Internacional. DOI: $10.32870 /$ sincronia.axxii.n74.18b18

\section{Patricia Martínez Cruz}

Escuela Nacional Preparatoria 6 "Antonio Caso" / Universidad Nacional Autónoma de México marcuztine@yahoo.com.mx

(MÉXICO)

Recibido: $29 / 03 / 2018$

Revisado: 24/04/2018

Aprobado: $14 / 06 / 2018$

\section{RESUMEN}

En este artículo se analizan, con base en las leyes de la Gestalt y en el contexto del franquismo (19661974), algunos poemas visuales del escritor español José Luis Castillejo, quien realiza su obra bajo una poética a la que llama "Escritura no escrita", la cual recibe influencia de Fluxus y del budismo zen. Se trata de una poética que pretende alcanzar la experiencia de lo inefable a través de la belleza y del valor simbólico de la grafía.

Palabras clave: José Luis Castillejo. Poesía visual. Poesía experimental. Franquismo. Poesía y budismo.

\section{ABSTRACT}

In this article some visual poems by the Spanish writer José Luis Castillejo are analyzed, based on the Gestalt Laws and on the context of the Franco regimen (1966-1974). José Luis Castillejo writes based on a poetics called "Unwritten writing", which is influenced by Fluxus and zen Buddhism. The poetics of Castillejo tries to achive the experience of the ineffable through the beauty and the symbolic value of the spelling.

Keywords: José Luis Castillejo. Visual poetry. Experimental poetry. Francoism. Poetry and buddhism. 
José Luis Castillejo (Sevilla, 1930 - Houston, 9 de septiembre de 2014) basa su producción escrita en una singular teoría sobre la escritura, influenciada por el budismo zen, el cual repercute primero en Zaj, el colectivo artístico al que el escritor se sumó de 1966 a $1969^{1}$. Bajo este influjo, mundo, realidad y vida tratan de presentarse principalmente como experiencia de libertad y comprensión de lo inefable. La grafía se escribe fuera de la significación convencional; pues colocada desnuda, se pretende suscitar vivencias artísticas que tratan de erguirse por encima de la represión política y cultural de la época, respuesta de un escritor que, habiendo observado el exterior, ${ }^{2}$ pudo comparar y ser partícipe de las acciones de un grupo de artistas que, como él, estaban intranquilos por lo que descubrían en otros países.

Zaj fue una oportunidad para liberarse de las normas impuestas por la dictadura de Franco, las cuales mantenían anquilosada la producción artística y cultural. Zaj fue un movimiento que representó una manera diferente de ver la realidad y, por consiguiente, de actuar. Esther Ferrer, una de las partícipes, define al movimiento como: "Zaj es una posibilidad llevada a la práctica" (Citado en: Luna, 2015, p.9). Ciertamente una posibilidad inesperada, extraña y reveladora que involucró a músicos, pintores, escultores, entre otros, quienes se desplazaron y transitaron por otras disciplinas al realizar poesía visual, performances, mail-art y happenings; además de elaborar los primeros libros de artista. Este actuar desconcertaba tanto al público como a los encargados de ejercer el poder. No porque las acciones atacaran directamente el sistema dictatorial, sino porque la gestualidad, elemento artístico base y, a veces único, en sus conciertos resultaba sospechosa, a veces molesta y otras divertida, según el observador. La inusual propuesta se conectó con el deseo social de transgredir las imposiciones. Esther Ferrer narra:

En el contexto de aquellos años, en España todo era política. Por ejemplo cuando Juan Hidalgo, Walter Marchetti y yo hacíamos ZAJ en Bilbao o en otros lugares, normalmente

\footnotetext{
${ }^{1}$ Con Zaj editó en 1967, La caída del avión en el terreno baldío, título tomado de Silence, de John Cage y en 1968, La política. El primero se presentó en hojas sueltas dentro de una caja, el lector podía leerlas como quisiera, por ello, se considera un libro de artista.

2 Primero como hijo de un exiliado en Francia y Argentina, luego como estudiante en Alemania, Francia, Inglaterra y Estados Unidos; posteriormente, como diplomático.
} 
no había mensaje político explícito salvo excepciones. Sin embargo, cuando hacíamos ZAJ delante de la gente, esta empezaba a gritar "Libertad", cantaban "La Internacional", de modo que un acto que no era explícitamente político se transformaba en un acto político porque el ambiente lo era. (Ídem, p. 28).

Comenzó la vigilancia, no porque sus acciones llegaran a las masas y éstas las comprendieran y aceptaran $^{3}$, sino porque se tiene miedo de lo que rompe esquemas y se sitúa abiertamente fuera de los cánones impuestos. Acostumbrados al modo franquista de hacer arte, costaba trabajo respirar otro viento. Sin embargo, aunque suscitar la expectación y la molestia era parte del juego Zaj, a veces cundía el desaliento en los partícipes, como se expresa en la correspondencia entre los integrantes de Zaj y Dick Higgins, integrante de Fluxus. Así pues, José Luis Castillejo escribe a Dick Higgins en abril de 1967:

Querido Dick:

Quiero darte las gracias por tu interés en mi libro. Quizá Juan te haya explicado que tenemos problemas para exportarlo. También tenemos otros problemas. La policía española ha llamado a Juan y a Walter para pedir información sobre Zaj. iFeliz Siglo Veinte! Respirar es pecar y nosotros hacemos un poco más que respirar.

Estoy escribiendo un segundo libro llamado "La política". Aunque no es directamente un libro sobre España, lo considero impublicable en las condiciones actuales. Incluso llevarlo a España podría ser comprometido. ¿Querrías tenerlo en depósito? Quizá pueda pensar en traducirlo al inglés y publicarlo con un seudónimo...Veremos. [...] Puedes imaginar que me siento deprimido. Hay un "frenazo" a la liberación en Madrid. Creo que en todo el mundo. (En Zaj y Higgins, 1998, pp. 70-71).

La práctica de arte interdisciplinar, el cruce de lenguajes y su postura subversiva que confrontaba no sólo el sistema político, sino las convenciones del mercado cultural, al realizar acciones únicas que

\footnotetext{
${ }^{3}$ Nada más lejano. Sólo unos pocos se volvieron hacia Zaj, por lo general el público reaccionaba con agresión y en caso de los libros publicados, estos tan sólo se repartían entre los amigos.
} 
permitían experiencias alternas, de otro modo ni pensadas, creaban incertidumbre en unos y asfixia en otros. De allí que se decidieran los segundos por el exterior. Así lo escribe Juan Hidalgo a Higgins en diciembre de 1971: "A causa de la muerte de mi padre, recibiré algún dinero e intentamos dejar España y sus problemas políticos y morales para siempre e irnos a vivir a Italia" (p. 80).

El extranjero se pensó como una oportunidad de liberación, aunque de cualquier modo, exilio, pues la comparación entre la manera de vivir en España y la manera de vivir en otras regiones fue una constante. Escribe Castillejo a Dick Higgins el 21 de enero de 1973:

El gobierno alemán nos ha invitado a Fernando Millán y a mí a una serie de lecturas sobre la NUEVA ESCRITURA. Nos han tratado espléndidamente. Hay interés por esta ESCRITURA sin palabras y hasta a veces sin letras. Ser escritor aquí no resulta tan malo como en la mayoría de otros sitios. (p. 87).

Escritura sin palabras, música sin notas, pintura sin pincel, etc. resultaban muy extrañas en una sociedad reacia al cambio. Zaj construyó un puente entre el interior y el exterior, entre la servidumbre y la libertad y entre una única forma de concebir la realidad y otras muchas posibilidades. La inconformidad con lo estipulado y el anhelo de renovación situaron al movimiento fuera del franquismo, pues intuían que había algo más. Ese algo más que los hizo voltear hacia el sin sentido, la vacuidad y lo inefable. Si el lenguaje artístico convencional establecía servidumbre y estancamiento, había que buscar más allá. John Cage y el budismo zen se incorporaron a la teoría y la práctica artística de Zaj. Esto desembocó en la elaboración de La nueva escritura, la propuestareflexión de José Luis Castillejo, sobre la escritura alejada de la palabra o mejor, del enunciado narrativo, descriptivo, argumentativo, con el cual se manipula la realidad o con el cual se manifiesta una única forma de ver, la interpretación de una sola persona a digerir por un lector adiestrado a leer igualmente, de una única determinada manera. El acto de escribir en La nueva escritura rechaza el enunciado, la historia, la descripción, la música, la pintura, el dibujo, la caligrafía. Queda el signo, desnudo de todo ornamento y de todo pensamiento, en un intento por librarlo del lenguaje, el cual según Zhuang Zi es "artesano de una construcción de nosotros mismos y de nuestra realidad, que, al 
designar las cosas las manipula" (citado en: Robinet, 1999, p.28). La realidad descrita por el enunciado sólo es una posibilidad entre muchas. La escritura de Castillejo intenta suscitar experiencias antes inconcebibles, en las cuales se sea partícipe de la libertad buscada, pretensión de hacer percibir lo inefable: "La escritura que yo busco es la que libera de la marca, la que no siempre está escrita. Símbolo de lo absoluto, de la totalidad, de la integración de los contrarios, del Tao, de la Totalidad..." (Castillejo, en entrevista con Mancebo, 1995). Por ello, esta nueva escritura está dirigida sólo a unos pocos, a quienes les interese ${ }^{4}$, pues dice Zhuang Zi: "No se le puede hablar del océano a una rana de pozo; está atada a su espacio. No se le puede hablar del hielo a la efímera de verano; está limitada por su estación" (Citado en: Robinet, 1999, p.31).

Castillejo se caracteriza por limpiar la forma utilizando los materiales mínimos, quizá esto debido al propósito de hacer vivencia lo inefable; parece volcarse en el recipiente para tratar de percibir el contenido, crea una obra que intenta hacer percibir las posibilidades múltiples de lo no escrito: "Greenberg" [dice, Castillejo] ha sido una gran influencia. Me enseñó que no bastaba con ver sino que había que 'ver' y 'ver' y 'ver' y que había que 'ver' lo no dicho, lo no hablado, lo no escrito, es decir la 'forma' o los 'arquetipos'”' (en entrevista con Mancebo, 1995).

Esta manera de concebir la escritura pretende comunicar que el vacío o la vacuidad son posibilidades de llenado; es decir, la pretensión de expresar el constante movimiento incluido en la quietud. Sin embargo, Castillejo se contradice en algunos momentos en su propuesta teórica, sobre todo respecto al contenido simbólico de la grafía o trazo. Escribe en El camino de la escritura moderna (1967):

Una escritura actual ha de ser libre y directa y por lo tanto no simbólica ni descriptiva. No debe buscar posesión alguna, ya sea real o ficticia, abstracta o concreta de las cosas, ni siquiera de los propios materiales de la escritura (Citado en: López Gradolí, 2008, p. 157).

\footnotetext{
${ }^{4}$ Las publicaciones de Castillejo estaban financiadas por él, eran casi manuales y las repartía a sus amigos. Aún así libros como La caída del avión en terreno baldío o The book of i's son piezas referentes en la poesía experimental y en los libros de artista.

${ }^{5}$ Clement Greenberg, el crítico de arte estadounidense que apoyó el Expresionismo abstracto y al pintor Jackson Pollock.
} 
Para luego reiterar en entrevistas y escritos su intención de resaltar el simbolismo, resonancia del inconsciente, arquetipos ocultos en la profundidad: “Mi letra no es la letra neurótica de que habla Lacan porque no es una 'marca' sino un 'símbolo'" (en entrevista con Mancebo, 1995). La liberación de la escritura, bajo este supuesto, implicaría hacer ver o reconocer los arquetipos (como tomar conciencia de ellos), para recuperar la capacidad de significar: "En la nueva escritura la abstracción no es total. Cada letra tiene restos semánticos históricos, psicológicos, gráficos. Potenciar esos restos que se despreciaban, como si no fueran escritura, es lo que intenta una nueva escritura o moderna escritura" (Castillejo, citado en López Gradolí, 2008, p. 172).

La concepción de la nueva escritura se relaciona estrechamente con la visión budista en la cual la cavidad vacía del recipiente permite la percepción de las posibilidades infinitas de llenado. Hacer ver las fases múltiples de la vacuidad, se convierte en la tarea principal, pues se pretende realizar una vuelta de tuerca, recuperar resonancia:

El hombre contemporáneo sólo está burocráticamente escrito en los números de su tarjeta de identidad pero esa escritura ya no tiene "resonancia", como la tenían los "nombres de antes", que creaban y eran parte de la historia. ¿De qué sirve tener un nombre cuando ya nadie es nadie ni nada es nada? (Castillejo en entrevista con Mancebo, 1995).

El sinsentido lleva al sentido. La no escritura a la escritura, la vacuidad a lo pleno. Así pues Castillejo declara:

La escritura no escrita es el otro lado (generalmente inconsciente) de la escritura escrita. Lo absoluto no puede describirse y un escritor que aspira a lo que hay que aspirar se enfrenta con lo inefable. Lo que está más allá de las palabras, de las letras, de las imágenes que sirven a los poderes fácticos ilusorios. (Castillejo en entrevista con Mancebo, 1995). 
La aprehensión de lo que hay más allá, sólo se puede obtener de una no escritura, es decir, una escritura a la que se le ha quitado la marca, la predisposición para leer de una determinada manera, buscando de antemano significados, prolongación de una determinada política cultural. Por lo tanto, leer se entiende como una visión manipulada de la experiencia. La salida que propone Castillejo es la escritura no escrita "la de los arquetipos, es inextinguible porque no marca, sino que es el opuesto complementario de la escritura. Precisamente, el símbolo se completa con una transformación" (Castillejo en entrevista con Mancebo, 1995). Bajo esta perspectiva, la escritura no escrita sería para el autor la oportunidad de tener experiencias de libertad, significaría:

La salida del mundo ilusorio y mediatizado de las imágenes que nos aprisionan, la salida de la cárcel. Cristo, Buda, Shakespeare, Cervantes, Nagarjuna... Ellos nos leyeron las escrituras no escritas. No se trata solo de ver sino de "ver" para poder leer y escribir. No se trata de leer sino de "leer". (Castillejo en entrevista con Mancebo, 1995).

La escritura y la no escritura actúan o se conciben como complementarias e integradoras, dependen mutuamente, existe una porque existe la otra. En este supuesto, explica Castillejo:

La escritura no escrita es el otro lado (generalmente inconsciente) de la escritura escrita [e ir tras esta escritura no escrita significa] una búsqueda de la realidad reprimida, una salida de la cárcel. Mi intención no es incendiaria sino integradora (mis ejemplos: Matisse, Pollock, Fitzgerald). La realidad actual si es incendiaria y asesina. (Citado en: López Gradolí, 2008, p. 179).

Una realidad manipuladora y tirana, en gran medida construida con lenguaje, la construcción de discursos justificadores del dominio de unos sobre otros, los cuales una vez institucionalizados se extienden a todos los campos de la vida cotidiana y se convierten en costumbres que son difíciles de erradicar. El problema no es el lenguaje, sino el uso del lenguaje. La propuesta de Castillejo es una búsqueda de pureza, la vuelta a casa: "La nueva escritura que deseo hacer nada tiene contra la palabra hablada y sólo es enemiga de la dominación verborreica, pretenciosa, trivial o ajena al arte 
de la escritura" (p. 198). La vuelta a casa significa concientizar la esencia, por decirlo así, de la escritura. Por ello se comprende que un escritor es un escritor y no un psicólogo, un biólogo o sociólogo, ni dibujante o artista plástico. Castillejo busca la autonomía en la escritura, casi como si buscara el absoluto. Sin embargo, la idea taoísta, según Robinet (1999) de que "una afirmación implica la posibilidad de su negación" (p. 15), que los contrarios se incluyen y se originan mutuamente, conduce al planteamiento de que nada es absoluto, y esta creencia es la fuente de inspiración del autor:

Rien n'est absolu. Ce que je veux dire et ça c'est mon message, je m'inspire dans le bouddhisme, rien n'est absolu. II n'y a pas une vision d'un tableau absolue, pour toujours. II n'y a pas une écoute absolue. On écoute à la maison, un jour, et un autre jour on écoute en public et ce n'est pas la même écoute. II y a des éléments communs, mais ce n'est pas exactement la même chose. L'identité, comme dit le bouddhisme, la croyance dans une identité permanente ou une nature propre permanente c'est une illusion. Dans le langage ordinaire, nous croyons à la même chose, nous croyons que la chaise est la chaise tout le temps, que la personne est la personne. Ce n'est jamais la même chose. Je pense qu'on peut dire que c'est plus pratique de partir de l'impermanence que de la permanence. Je ne dis pas que l'impermanence c'est un absolu total, ce serait faire de la métaphysique. La physique ne nous permet pas de dire des choses métaphysiques, mais je pense que du point de vue pratique, c'est plus intéressant d'admettre une impermanence qu'une permanence.

[Nada es absoluto. Es lo que quiero decir y ése es mi mensaje, me inspiro en el budismo, nada es absoluto. No hay una percepción única de un cuadro. No hay una escucha absoluta. Un día escuchamos en casa y otro día escuchamos en público. No se trata de lo mismo. Hay elementos comunes, pero no es exactamente lo mismo. La identidad, como dice el budismo, la creencia en una identidad permanente, o en una naturaleza propia permanente, es una ilusión. En el lenguaje ordinario, ocurre lo mismo, creemos que la silla es la silla, que la persona es la persona. Pero nunca se es lo mismo. Creo que es más práctico partir de la impermanencia que de la permanencia. No digo que la 
impermanencia sea el absoluto, eso sería metafísica. La física no nos permite decir cosas metafísicas, pero creo que, desde el punto de vista práctico, es más interesante admitir una impermanencia que una permanencia]. (Castillejo en entrevista con Létourneau, 2000).

Pensar la escritura en términos taoístas es concebir que se puede provocar una experiencia artística abierta y múltiple, capaz de hacer sentir la realidad, no sólo conformada por la represión, pues ésta únicamente es una pequeña parte de la realidad compleja en la cual los contrarios se reconcilian y hacen sentir en esa reconciliación la experiencia de ese más allá, lo inefable:

La realidad es abierta cuando se presenta al mismo tiempo como un todo y como un conjunto de resistencias que se oponen a su apropiación. Por eso, realidad no es posesión, no es el conjunto de todas las posesiones, no es un pleno que se oponga al vacío. La realidad no es ni plenitud ni vacío. Es la vacuidad u origen dependiente de los sucesos. (Citado en: López Gradolí, 2008, p. 215).

El punto de partida para llegar a tal visón sobre la escritura es el reconocimiento de la relatividad o la incertidumbre. Pues la pretensión de inducirnos a dicha experiencia parte de reconocer "que poco o nada es seguro" (p. 152). Nada puede ser afirmado como la verdad última, pareciera que la condición es el dinamismo y la flexibilidad. La percepción de la realidad con base en los cambios de forma. Por esa causa ceñir la forma a una determinada manera de pensar el arte es reducirla a la servidumbre: "en las artes como en la vida no debe haber servidumbres" -escribe Castillejo ( $p$. 155). Ni siquiera una forma es fija cuando se encuentra en un soporte. ¿Qué hace Castillejo para inducir la reflexión sobre el movimiento flexible? Propone que las grafías no ocupan el espacio, sólo están, por ello pueden cambiar de lugar o de forma.

La concepción taoísta del espacio como extensión es útil para explicar lo anterior, pues en ella las cosas no alteran el espacio por su volumen, sino por las relaciones que establecen entre 
ellas. Es decir, el predominio de las relaciones de las cosas en el espacio implica que puedan cambiar de lugar o de forma:

Los signos de mi escritura están en un sitio, pero no la ocupan [...] Mis letras están muy bien en un espacio específico, pero podrían estar igualmente bien en cualquier otro lugar. Se resisten tanto al 'privilegio' de ocupar un lugar como a otorgar a un lugar el privilegio de ser ocupado por ellas. (p. 156).

La flexibilidad de la grafía es consecuencia del intento del escritor por hacer percibir una realidad compleja, en la cual las posibilidades son múltiples y mutantes:

La escritura es una notación que tiende a establecer el mayor grado posible de la realidad. Como la realidad es abierta, la escritura ha de ser libre, es decir, ha de dar constancia de la libertad. Lo escrito, escrito está, la realidad ha sucedido, pero pudo haber sido de otra manera. (p. 236).

La propuesta conlleva la idea de alterar o inducir otra u otras formas de leer; primero, lo inusual sorprende, se produce el extrañamiento; de allí las reacciones de rechazo o aceptación y el disparo de la reflexión sobre el hecho observado, llamado por su autor escritura artística. Segundo, tal abstracción nos presenta desafíos y posibilidades de otro modo, no imaginadas; el involucramiento del lector a través de la abstracción. Escribe Castillejo:

La abstracción tiene como finalidad disminuir el automatismo con que se interpreta convencionalmente un signo. Cierto grado de abstracción en la escritura permite, no sólo disminuir la fuerza del automatismo que transforma inmediatamente el signo escrito en hablado, sino también que el signo escrito respire libremente, es decir, establezca una o varias posibilidades escritas. Libertad que supone una opción, que una cosa sea o no sea posible entre varias, cierto margen. Libertad significa dejar cierto margen de libertad al signo escrito. (p. 223). 
La intención de manifestar o hacer descubrir la experiencia de lo inefable es bastante ambiciosa; despojar a la palabra de cualquier significado también lo es, así como apelar a un simbolismo que se encuentra más allá del lenguaje, pero la propuesta de Castillejo sí nos plantea considerar otras posibilidades de otro modo impensables. Utiliza el mínimo de recursos para ello, repetición, disposición en el espacio, escritura de una sola grafía, página en blanco. Por ello, muchos lo han clasificado como minimalista; sin embargo, él no cree ser un escritor minimalista:

Je crois que tout ce qu'on dit, d'une façon ou l'autre, abstraite ou concrète, on le dit métaphoriquement, même la science est métaphorique quand elle parle des choses. Le littéralisme c'est une chose très mauvaise à notre époque, c'est pour ça que je fais une critique très forte du minimalisme et je comprends que les gens pensent que Le Livre des $i$ est minimaliste. Je ne suis pas un minimaliste. Je pense que je ne crois pas à cette sorte de réduction, je crois que je ne crois pas à la réduction à l'objet ou à la littéralité. La littéralité c'est une métaphore comme tout. Le plus que je peux dire à la faveur de la littéralité, c'est que ça peut être utile pour certaines choses, mais que c'est une métaphore aussi comme toutes les autres métaphores.

[Creo que todo lo que se dice, de un modo u otro, abstracto o concreto, se expresa metafóricamente; incluso la ciencia hace uso de la metáfora para explicar. La literalidad es algo muy malo en nuestro tiempo, por eso hago una crítica muy fuerte al minimalismo. Comprendo que la gente piense que The Book of $i$ es minimalista, pero no soy un minimalista. No creo en ese tipo de reducción, no creo en la reducción del objeto o en la literalidad. La literalidad es una metáfora como todo. Lo máximo que puedo decir a favor de lo literal es que puede ser útil para algunas cosas, pero que es una metáfora como todas las demás metáforas]. (Castillejo en entrevista con Létourneau, 2000).

La búsqueda de lo inefable lo aleja de la metáfora y de la literalidad. Conforme reflexiona más sobre la escritura, se va quedando sólo con el trazo, como en The book of i's, El libro de las dieciocho 
letras y El libro de la letra y otros libros, inéditos ${ }^{6}$. Estos libros presentan en común el trazo reiterativo de unas cuantas grafías, colocados bajo determinada consigna, por ello, un tanto al azar y un tanto no azar. Por ejemplo The book of i's, de 23×15.5 cm., encuadernado en pasta dura de tela gris, consta de cuatrocientas páginas en las que la protagonista es la $i$ de 16 milímetros de altura, colocada en el centro de la página o no colocada, pues depende de la consigna, si la palabra en inglés que designa el número de página contiene una i, ésta se coloca en el centro. Son numerosas las páginas en blanco.

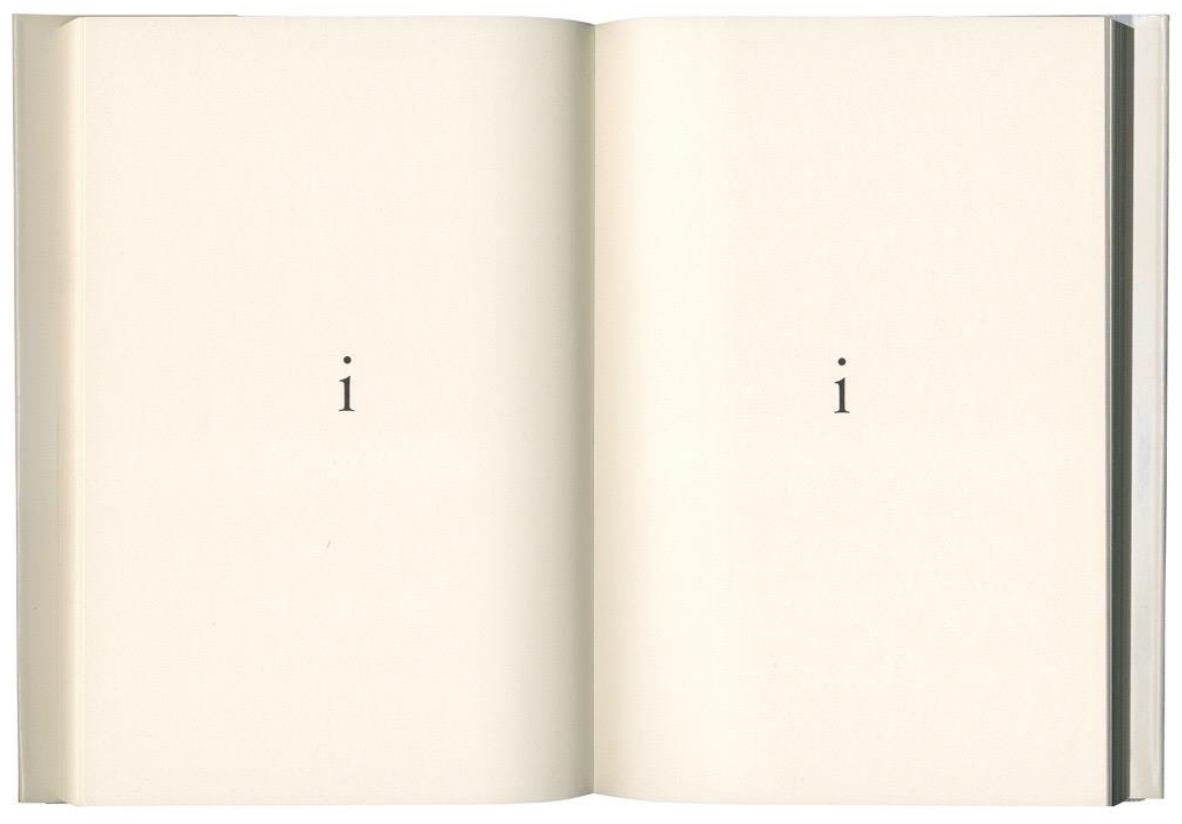

Castillejo, J.L. (1969). The book of i's, s.p.

En cierto sentido, The book of i's, parece ser un homenaje a libros antiguos, como el I Ching, cuyo principio fundamental es la transformación en la cual los opuestos fluyen de uno al otro. The book of i's es un universo simbólico y, por ello abierto, pues el cambio es la constante, el principio.

${ }^{6}$ El autor depositó en la Staatsgalerie de Stuttgart obra en la que trabajó desde 1969: El libro de las cuatro figuras, El libro de los tríos, El libro de las mitades, El libro del libro, El libro de los errores, etc. 
Páginas y páginas en blanco, la i al centro en un par, la i con una página en blanco. Aunque la consigna pudo haber sido otra, por ejemplo, tomar otro idioma, el resultado hubiera sido similar, pues la elección sólo es una eventualidad. La i interviniendo la página o la página interviniendo el trazo, como sea, la interacción de la mancha tipográfica y la página nos conducen a la visión de lo permanente - la grafía colocada en el mismo sitio- y lo impermanente - se trata de otra i, contenida en otra palabra, colocada en otro espacio-. De este modo se anula el contrario o mejor, se integra en una experiencia artística.

Ahora bien, Castillejo dota a la grafía de una inteligencia o, digamos, de autonomía, se pronuncia a favor del gesto, el trazo de la letra, el cual no posee el espacio, sino está colocado en él. La colocación en el espacio, un tanto azarosa, como ya se mencionó, bien podría haber sido otra, lo relevante son las relaciones que se establecen entre página y gesto o entre gestos, a veces repetidos en toda la página con un especial orden, como si se tratara de la pronunciación de un mantra, lo que crea un ritmo, percibido monótono, sin embargo por ello significativo y liberador. Sin espacio ni tiempo para otra visión o pensamiento, pues aprehendidos por la inusual escritura, se detiene el proceso del acostumbrado modo de leer y ver.

Castillejo aspira a la profundidad, vaciando primero, para posibilitar el llenado. Su escritura pretende ser una escritura de la vacuidad. El término complejo que, incluso ha dado problemas en su región de origen, Oriente, por su multifacética faz. La vacuidad no se refiere al vacío, sino a un espacio que, explica Robinet (1999) "acoge [...] la distancia entre las cosas o los seres, que permite que haya 'juego' [...], la ausencia de pensamientos y deseos, un 'blanco' del que puede surgir todo" (p. 158).

Su obra "Censo de vacuidades" de La caída del avión en el terreno baldío es más que significativa de lo anterior: 


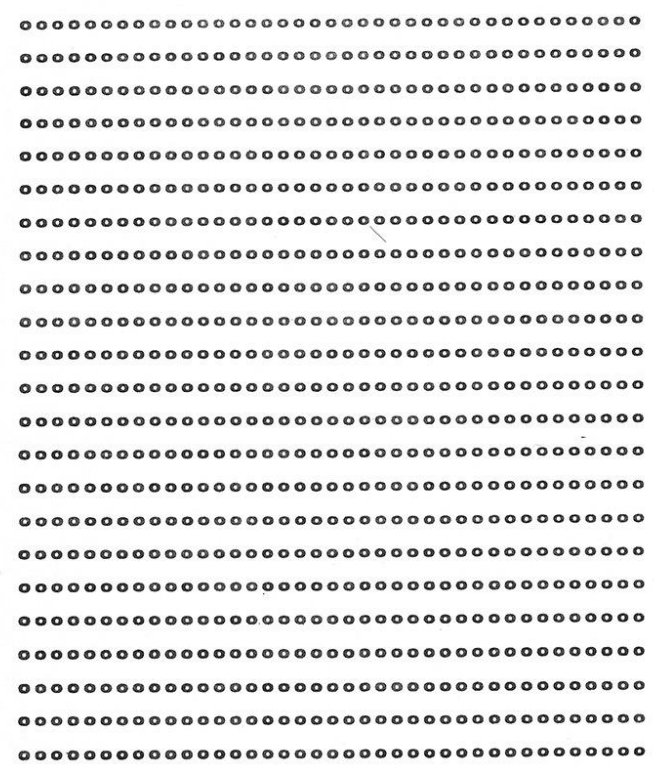

Castillejo, J. L. (1967). La caída de un avión en terreno baldío, s.p.

La técnica usada en esta obra es por supuesto la repetición del trazo de círculos de manera uniforme en la página blanca, aunque no igual, pues los trazos se colocan de manera serial y periódica pero no son iguales. Existen relaciones de verticalidad y horizontalidad, destaca esta última por el recuerdo que se tiene de la página escrita en un libro en cualquier lengua occidental, sin embargo, la verticalidad ${ }^{7}$ de la página sugiere un monolito, una piedra, y la grafía, la incisión, el

\footnotetext{
${ }^{7}$ Castillejo habla sobre su preferencia por la verticalidad en entrevista con Létourneau (2000): "Je veux parler des éléments constants de mon écriture; la verticalité. Pour moi, c'est une écriture assez masculine. Vous savez, la verticalité, c'est l'esprit. Moi je parle de l'esprit psychologique, je ne parle pas de l'esprit métaphysique, théologique et tout ça. Je suis beaucoup plus avec le pied à terre et, psychologiquement, la verticalité c'est cette fonction de notre personnalité qu'on appelle l'esprit. Vous savez que le tableaux sublimes en peinture ont la verticalité. Aussi, la verticalité détruit un peu l'élément objet du livre. Je ne veux pas faire ni de livre objet ni de livre de luxe. La verticalité fait que le livre soit plus livre et moins objet".
} 
gesto que trata de poner orden y registrar la memoria. De allí la uniformidad, la quietud y el equilibrio.

Por la Ley de prägnanz, el escrito se ve de manera regular, ordenada y simétrica; por la Ley de proximidad, los trazos se observan en relación estrecha; sin embargo, los círculos no son iguales, por lo que parece ser una invitación a contemplar los pequeños matices dados en la uniformidad; los círculos bien podrían escaparse de la página que les da cabida y seguir extendiéndose por el espacio, de manera similar, uniformemente, a la horizontal y a la vertical, uno junto a otro, siendo parte del registro de la certeza de la incertidumbre, la cual tampoco es una certeza. Explica Robinet (1999):

La noción de vacuidad está para significar la inconsistencia del mundo, el hecho de que no tiene fundamento metafísico, que cada ser se apoya en el conjunto y en cada uno de los demás, e inversamente, como un castillo de naipes. La búsqueda de un fundamento (ya lo decía Zhuang zi, como hemos visto) no tiene fin, porque, ¿̇en qué fundamento apoyarse para encontrar un fundamento? Hay que resignarse a renunciar a la búsqueda de una verdad última. Mas no por ello hay que pensar que al hacer eso se ha encontrado algo, una verdad. Sería equivocarse completamente dando una realidad a una ausencia. (p.160).

De esta manera, se manifiesta la transformación latente y el movimiento en la estabilidad o quietud. En otros poemas, la colocación de la grafía creará dinamismo e inestabilidad, sin embargo, al mismo tiempo, también la sensación contraria. Como en la siguiente página de El libro de la letra.

[Quiero hablar sobre uno de los elementos constantes de mi escritura: la verticalidad. Para mí, mi escritura es bastante masculina. Usted sabe, la verticalidad es el espíritu. Estoy hablando del espíritu psicológico, no estoy hablando de lo que se entiende en metafísica, en la teología. Soy mucho más realista y, psicológicamente, la verticalidad es esa función de nuestra personalidad que llamamos espíritu. Usted sabe que las obras sublimes de pintura tienen verticalidad. Además, la verticalidad destruye un poco el elemento objeto del libro. No quiero hacer ni un libro objeto ni un libro de lujo. La verticalidad hace que el libro sea más libro y menos objeto]. 


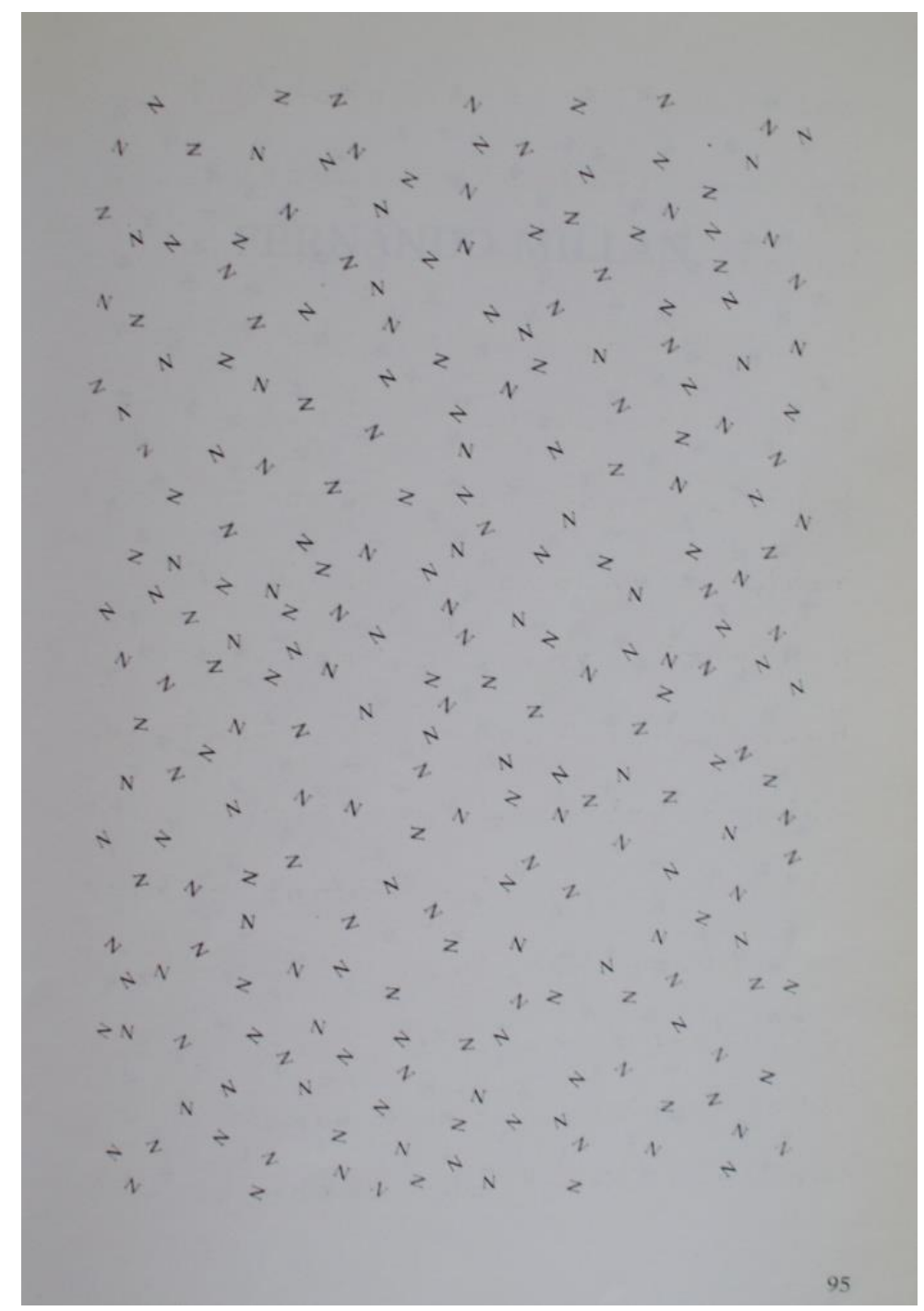

Castillejo, J. L. (1973), en Sarmiento, 1990, p. 95

En esta página, las grafías, al parecer colocadas aleatoriamente, forman una mancha tipográfica amplia y dinámica; una mancha que sugiere un enjambre, una parvada o tan solo partículas en movimiento. Estas posibilidades surgen por las leyes de prägnanz, de proximidad y de similitud. Sin embargo, bien podrían plantearse otras posibilidades. Lo interesante es la relación entre las grafías entre sí y con el espacio, pues la colocación aleatoria de las grafías, una N mayúscula o una Z, aportan cierta inestabilidad a la obra, más el énfasis de la diagonal en contraste con las delgadas 
verticales. La inestabilidad se neutraliza por la forma de la misma grafía, pues la N, igual que la aleph judía $\boldsymbol{\kappa}$, es una letra que lo mismo puede estar de pie o de cabeza, y mantener su forma. Lo mismo ocurre en el caso de la z. Además la colocación aleatoria es ordenada; ninguna grafía se encima con otra, entre ellas se encuentra suficiente espacio para guardar su independencia, o su autonomía; sin embargo, al mismo tiempo se presentan como parte de un cuerpo. Por analogía, como ya se mencionó anteriormente, un enjambre, una parvada o partículas. En términos taoístas podríamos pensar que la inestabilidad y el movimiento pasaron a la estabilidad y quietud del vuelo. El desequilibrio es aparente, pues el vuelo organizado persigue un fin, la unión del grupo lo consigue. De esta manera, Castillejo activa la energía de las grafías, en relación con y en el espacio. La obra en la que se "desnuda" al signo lo transforma, lo convierte en animal, persona, ave, partícula que, a su vez se comporta de determinada manera a partir del ojo del observador. Es así como la dialéctica de los opuestos que fluyen y se generan mutuamente crean una escritura que permite que la lectura sea abierta y múltiple y ¿por qué no? Libre. Si se oye el zumbido del enjambre, el aleteo de la parvada o el ir y venir de las partículas de polvo, quizá la escritura haya logrado ir más allá del lenguaje.

\section{Referencias:}

Castillejo, J. L. (1967). La caída del avión en terreno baldío. Madrid: Zaj.

Castillejo, J. L. (1969). The book of i's. Alemania: Edición del autor.

Létourneau, E. (2000). Conversation avec José Luis Castillejo. Obtenido el 9 de septiembre de 2017 de http://ici.radio-canada.ca/radio/navire/rencontres_castillejo.html

López, A. (2008). La escritura mirada. Una aproximación a la escritura experimental española. Madrid: Calambur.

Luna, D. (2015). Zaj. Arte y política en la estética de lo cotidiano. Madrid: Athenaica.

Mancebo, J. A. (1995). Entrevista a José Luis Castillejo. Obtenido el 10 de diciembre de 2017 de https://ruidera.uclm.es/xmlui/handle/10578/3534?show=full 
Robinet, I. (1999). Lao Zi y el Tao. Barcelona: José J. de Olañeta, Editor.

Sarmiento, J. A. (1990). La otra escritura. La poesía experimental española 1960-1973. Cuenca: Universidad de Castilla-La Mancha.

Zaj-y-Higgins, D. (1998, enero, 12). Correspondencia Zaj-Dick Higgins (1966-1973). Sin título, (5), 6188. 